\title{
Urdimento
}

Revista de Estudos em Artes Cênicas

E-ISSN: 2358.6958

\section{Meu quintal de casa é o mundo: Espaço, Corpo, Afeto e Dramaturgia em All About That Bass}

Aroldo Santos Fernandes Júnior

Para citar este artigo:

FERNANDES JÚNIOR, Aroldo Santos. Meu quintal de casa é o mundo: Espaço, Corpo, Afeto e Dramaturgia em All About That Bass. Urdimento, Florianópolis, v. 2, n. 38, ago./set. 2020.

DOI: http:/dx.doi.org/10.5965/14145731023820200028

Este artigo passou pelo Plagiarism Detection Software | iThenticate 
Meu quintal de casa é o mundo:

Espaço, Corpo, Afeto e Dramaturgia em All About That Bass

Aroldo Santos Fernandes Júnior ${ }^{1}$

\title{
Resumo
}

Este texto é um ensaio teórico que parte de inquietações sobre a videoperformance All about that bass produzida pelo artista Royce Cherdan Lee, também conhecido como Chubbeyoncé Lee. A videoperformance foi inspirada pelo videoclipe original de mesmo título, da cantora norte americana Meghan Trainor. Tem por objetivos refletir questões relacionadas ao espaço, ao corpo e ao afeto enquanto dimensões dramatúrgicas em produções audiovisuais postadas na plataforma digital do YouTube, a partir de conceitos como: Exotopia; Heterotopia; Dramaturgia do Espaço; Corpomídia e Mídia Propagável; expor a compreensão dos conhecimentos, das subjetividades e das intervenções cênicas e sociais relativas a essa videoperformance para criar um texto de natureza evocativa, metonímica, subjetiva, nervosa e citatória. Para tais objetivos faz-se uso da Escrita Performativa enquanto modo de realizar a escrita. Em All about that bass o quintal, os corpos que o habitam e o afeto que geram as ações são os pontos de interesse desse ensaio.

Palavras-chave: Corpo. Afeto. Espaço. Dramaturgia. Mídia.

My backyard is the world:

space, Body, Affection and Dramaturgy in All About That Bass

\begin{abstract}
This text is a theoretical essay that starts from concerns about the video performance All about that bass produced by the artist Royce Cherdan Lee, also known as Chubbeyoncé Lee. The video performance was inspired by the original music video of the same title, by the American singer Meghan Trainor. It aims to reflect on issues related to space, body and affection as dramaturgical dimensions in audiovisual productions posted on the YouTube digital platform, based on concepts such as: Exotopy; Heterotopia; Space Dramaturgy; Corpomidia and Spreadable Media; to expose understanding of knowledge, subjectivities and the scenic and social interventions related to that video performance to create an evocative nature of text that is metonymic, subjective, nervous and citatory. For such purposes, Performative Writing is used as a mode to perform writing. In All about that bass the backyard, the bodies that inhabit it and the affection that generate actions are the points of interest of this essay.
\end{abstract}

Keywords: Body. Affection. Space. Dramaturgy. Media.

Doutorando pelo Programa de Pós-Graduação em Artes Cênicas da Universidade Federal da Bahia (PPGAC/UFBA). Mestre em Artes Cênicas pelo Programa de Pós-Graduação em Artes Cênicas (PPGAC/UFBA - 2012). Graduado em Licenciatura em Dança e Dançarino Profissional pela Universidade Federal da Bahia (2002). Professor da Universidade Estadual do Sudoeste da Bahia, no Departamento de Ciências Humanas e Letras (DCHL/UESB). asfjunior@uesb.edu.br 
Mi patio es el mundo:

Espacio, Cuerpo, Afecto y Dramaturgia en All About That Bass

\section{Resumen}

Este texto es un ensayo teórico que parte de las inquietudes sobre la videoperformance All about that bass producido por el artista Royce Cherdan Lee, también conocido como Chubbeyoncé Lee. La videoperformance se inspiró en el video original del mismo título, de la cantante estadounidense Meghan Trainor. Sus objetivos son reflejar cuestiones relacionadas con el espacio, el cuerpo y el afecto como dimensiones dramatúrgicas en producciones audiovisuales publicadas en la plataforma digital de YouTube, basadas en conceptos como: Exotopia; Heterotopia; Dramaturgia Espacial; Corpomídia y Propagable Media; exponer la comprensión del conocimiento, las subjetividades y las intervenciones escénicas y sociales relacionadas con la videoperformance, para crear un texto de naturaleza evocativa, metonímica, subjetiva, nerviosa y citativa. Para tales propósitos, la Escritura Performativa se usa como una forma de escribir. En All about that bass el patio, los cuerpos que lo habitan y el afecto que generan las acciones son los puntos de interés de este ensayo.

Palabras-Clave: Cuerpo. Afecto. Espacio. Dramaturgia. Medios de comunicación. 
É o fundo do jardim, com certeza, é com certeza o celeiro, ou melhor ainda, a tenda de índios erguida no meio do celeiro, ou é então - na quinta-feira à tarde - a grande cama dos pais. É nessa grande cama que se descobre o oceano, pois nela se pode nadar entre as cobertas; depois, essa grande cama é também o céu, pois se pode saltar sobre as molas; é a floresta, pois pode-se nela esconder-se; é a noite, pois ali se pode virar fantasma entre os lençóis [...]

(Michel Foucault, As heterotopias)

Este texto é um ensaio teórico que parte de inquietações sobre a videoperformance All about that bass ${ }^{2}$ produzida pelo artista Royce Cherdan Lee, também conhecido como Chubbeyoncé Lee. A videoperformance foi inspirada pelo videoclipe original de mesmo título, da cantora norte-americana Meghan Trainor $^{3}$ e foi postada na plataforma digital do YouTube.

No processo de observação das narrativas acionadas pela videoperformance de Lee, houve de minha parte, uma necessidade muito particular de praticar o "exercício de abismar" proposto por Angela Materno em seu artigo O Olho e a Névoa: Considerações sobre a Teoria do Teatro. Para Materno, "abismar" seria "flagrar o espedaçamento e obscurecimento do visível implicados em tudo o que se mostra" (Materno, 2003, p.32). Encontro, nessas narrativas, a imagem metonímica de um abismo que pode, por vezes, parecer complexa, mas é do alto desse precipício que percebo toda uma paisagem possível e potente para alçar voos de análise. Em seu livro Seis propostas para o próximo milênio no capitulo da Leveza, Ítalo Calvino nos diz que "a gravidade detém o segredo da leveza" (1990b, p. 24), é com leveza que adentro o abismo metonímico da videoperformance de Lee tentando não me perder em seus labirintos.

Do alto desse precipício proponho refletir questões relacionadas ao espaço, ao corpo e ao afeto enquanto dimensões dramatúrgicas em produções

\footnotetext{
${ }^{2}$ Royce Cherdan Lee. All about that bass. Disponivel em: https://www.youtube.com/watch?V=X1bhpWQDT-4. Acesso em: 21 abr. 2020.

${ }^{3}$ Meghan Trainor. All about that bass (Official Music Video). Disponivel em: https://www.youtube.com/watch?v=7PCkvCPvDXk. Acesso em: 21abr. 2020.
} 
audiovisuais, na plataforma digital do YouTube, para tanto trago como articuladores de meus pensamentos os conceitos de Exotopia (Bakhtin, 1919), o qual, segundo Marília Amorim (2006, p. 95),"refere-se à atividade criadora em geral". O conceito de Heterotopia (Foucault, 1967), por sua vez, refere-se às "contestações míticas e reais do espaço em que vivemos" (Foucault, 2013, p.20). Já a expressão Dramaturgia do espaço (Barba, 1936), evoca a eficácia do espaço cênico enquanto dimensão dramatúrgica que desperta no espectador uma percepção de duplicidade. Corpomídia (Katz; Greiner, 2010, p. 130) pressupõe uma abordagem do corpo enquanto "processo co-evolutivo de trocas com o ambiente" e Mídia enquanto "processo evolutivo de seleção das informações que vão constituindo o corpo" (Katz; Greiner, 2010, p. 131). Mídia Propagável (Jenkins; Green; Ford, 2014, p. 24) diz respeito a "um modelo híbrido e emergente de circulação em que um mix de forças [...] determina como um material é compartilhado através de culturas e entre elas". O objetivo aqui é tecer a relação entre estes conceitos e um objeto que por sua característica ontológica existe enquanto modulação eletrônica no ciberespaço.

\section{Vídeo / Performance / Videoperformance}

Entre os anos de 1950 e 1960 surge na Europa e Estados Unidos uma complexa forma de arte que revelava algo de híbrido em sua natureza ontológica enquanto forma artística, o vídeo. Com seu surgimento, uma diversidade de movimentos artísticos, ideias teóricas e avanços tecnológicos, bem como ativismos políticos e sociais surgiram com ele. Para Arlindo Machado (2008, p.09), a "arte sempre foi produzida com os meios de seu tempo" e o vídeo não fugiu a essa lógica e em seu caminho histórico, como forma artística, sempre esteve estritamente relacionado e dependente do desenvolvimento da tecnologia.

De acordo com Cris Meigh-Andrews (2014), a partir de 1960 houve um grande desenvolvimento na tecnologia eletrônica e digital da imagem e estes avanços tecnológicos fizeram com que o vídeo deixasse de ser uma forma de arte cara e dispendiosa exclusiva da grande indústria televisiva, para se popularizar. Em 
meados dos anos de 1980 os dispositivos eletrônicos de vídeo gravação, passam a ser mais leves; a qualidade de registro da imagem deixa de ser granulada e cheia de ruídos, imperfeições ou baixo contraste e se torna mais acurada e com praticamente a mesma qualidade dos equipamentos utilizados pelas grandes instituições de mídia televisiva. O desenvolvimento tecnológico dá grandes saltos de aprimoramento e em meados da década de 1980 surgem os primeiros computadores de uso pessoal e doméstico. A roda de sofisticação da tecnologia continua girando e, em meados dos anos 1990, toma proporções globais com a criação da Internet. Todas essas rápidas mudanças influenciaram e atualizaram as estéticas de vídeo-arte, mas é em 2005 com a criação da plataforma digital YouTube e com a popularização dos smartphones, ao final da década de 2010, que acontece uma verdadeira mudança de paradigma na utilização da linguagem de vídeo.

A criação da Internet em meados de 1990 e a criação da plataforma Digital YouTube gerou a possibilidade "de vozes comuns serem ouvidas e eventos cotidianos e corriqueiros serem vistos em várias partes do globo, gratuitamente" (Fernandes Júnior, 2015, p. 29). Isso permitiu uma participação que expandiu as noções previas de fazer artístico, ignorando barreiras financeiras impostas pela mídia convencional, como filme e televisão.

Néstor Garcia Canclini (2012, p. 52) diz que:

Os novos hábitos gerados nos usuários da rede e as misturas de formatos e alianças entre produtores de conteúdos visuais, textuais e software estão incidindo nos espaços da arte, desde os museus até as bienais, as feiras e os sites especializados da internet. Alteram-se neste processo os vínculos entre criação, espetáculo, entretenimento e participação; entre o que até poucos anos atrás se organizava sob categorias de culto, popular e de massa; entre o local, o translocal e o global; entre autoria, reprodução e acesso; entre elaboração simbólica e intensidade de estimulação sensual direta.

Na continuação do pensamento sobre conteúdos artísticos gerados e que são compartilhados na plataforma YouTube, observa-se a partir do pensamento de Henry Jenkins, em seu livro Cultura da Convergência (2009) que as 
experimentações alternativas na música dentro da cultura punk geraram novas possibilidades de sons, artistas e relações com os consumidores e essa lógica de produção do filme digital para o YouTube está equiparada a esse pensamento da cultura punk e o que, em algum momento, foram consideradas atividades marginais, passaram a ser cada vez mais normais, e conteúdos produzidos por amadores se tornaram alvo da atenção das mídias tradicionais de massa.

A produção de videoperformances que utilizam enquanto recurso à paródia, realizadas por fãs de artistas consagradas da indústria musical pop, gravadas a partir do celular e postadas na internet, fazem parte desse processo apontado tanto por (Canclini, 2012) quanto por (Jenkins, 2009) e é nesse contexto que encontro Royce Cherdan Lee e sua videoperformance All about that bass'.

Royce Cherdan Lee ou Chubbeyoncé Lee como é conhecido na internet, é um jovem de 24 anos, de Cebu, nas Filipinas, que com seu grupo de dança TeamAspo, posta pequenas videoperformances, em que (re)criam, (re)formulam e (re)instauram cenas, pensamentos, narrativas, sentidos e valores da indústria cultural pop, a partir de seus próprios recursos e pontos de vista. Sua vasta produção de videoperformances curtas, dividida em três perfis no YouTube, a saber: Royce Cherdan Lee (perfil pessoal), Chubbeyoncé Lee ( 2 o perfil pessoal); TeamASPO (perfil do grupo) se redimensiona constantemente pelas frequentes postagens numa retroalimentação do fluxo midiático.

A canção All About That Bass, foi composta por Meghan Trainor e Kevin Kadish e foi lançada em 30 de junho de 2014, tendo conseguido 171.796 visualizações até dezembro do mesmo ano. Sete meses depois, no dia 06 de fevereiro de 2015, Royce Cherdan Lee lança sua versão do videoclipe da música, o sucesso de seu vídeo foi estrondoso e em apenas um dia conseguiu 7.221 visualizações.

Em All about that bass, Lee e seu grupo de dança TeamAspo realizam sequências coreografadas de movimento e a dublagem da música. Utilizam

${ }^{4}$ Tanto a música da Meghan Trainor quanto a videoperformance do Royce Cherdan Lee tem o mesmo título. No texto apresento com grafias distintas respeitando as formas que foram grafadas em seus respectivos canais no YouTube, a saber All About That Bass com todas as iniciais das palavras em maiúsculo para o Videoclip da Meghan Trainor e All about that bass com apenas a primeira letra da frase em maiúsculo para a videoperformance do Royce Cherdan Lee. 
materiais como baldes, panelas, cabos de vassoura, guarda-chuva e leques para (re)construir alguns dos efeitos de edição do videoclipe original, sem contudo fazer qualquer corte de edição em seu vídeo. O espaço em que estas sequências acontecem é um corredor no fundo de uma casa, em Cebu nas Filipinas. Maior parte de suas videoperformances são realizadas em espaços domésticos como o quintal de casa ou sala ou o quarto de dormir, ou ainda, espaços como terrenos abertos e baldios ou na praia. Qualquer lugar pode ser cenário para suas videoperformances. Em All about that bass o quintal, os corpos que o habitam e o afeto que geram as ações são os pontos de interesse desse ensaio.

\section{Espaço / Ciberespaço / Ciberquintal}

O quintal em All about that bass é um corredor estreito, um espaço rústico e pouco elaborado que delimita o fundo e a lateral de duas casas, com aparência de lotes à beira mar. O professor de História da Universidade da California (UCLA), Russell Jacoby (2007, p. 62) aponta que “[...] os espaços não planejados das cidades possibilitam os jogos e as brincadeiras, tanto hoje quanto no futuro".

Falar do espaço do quintal é falar de um espaço afetivo, de memórias de infância, das casas, em cidades do interior, com grandes espaços abertos em que várias atividades aconteciam, desde as mais cotidianas às mais eventuais. 0 quintal é um espaço externo dentro da privacidade da casa, um espaço que nos abre a imaginação, com sua imensidão de possibilidades, uma "imensidão íntima" como nos diz Gaston Bachelard (1994), em sua poética do espaço.

Na epígrafe extraída do texto As heterotopias, Michel Foucault, refletindo sobre espaços existentes, afirma que a lógica dos adultos atribuiu função e finalidade, as crianças conseguem (re)significa-los em zonas imaginadas. Acrescenta, ainda, que estes espaços, entre todos os distintos lugares que se pode viver, são os que "se opõem a todos os outros, destinados, de certo modo, a apagalos, neutraliza-los ou purifica-los" (Foucault, 2013, p.20).

Num breve movimento autoetnográfico retorno à minha infância, num 
momento de brincadeira no quintal, para pensar o exercício da imaginação. Era uma manhã ensolarada de sábado, em Vitória da Conquista, eu tinha uns 08 anos de idade, era dia de minha mãe trocar os lençóis das camas. Eu aproveitava enquanto ela forrava as camas com os lençóis limpos e pegava os usados para, num corredor estreito do quintal, montar uma cabana de lençóis. Usava para montar a cabana, pedaços de uma antiga estrutura de uma balanço de metal que havia quebrado e os prendedores de roupa. Construía uma cabana com vários espaços internos que eram divididos com os lençóis abertos e presos. Ficávamos eu e meu irmão nessa cabana, a nos inventar como proprietários daquele espaço, até minha mãe descobrir a traquinagem e acabar com nossa brincadeira.

O espaço desse quintal de minha infância era razoavelmente grande, cimentado e sem grandes atrativos, apenas esse corredor que tinha um pequeno e estreito portão azul de madeira que dava acesso à rua. Esse corredor era interessante, pois continha em uma de suas paredes o espaço de uma janela que era pouco usada, quase sempre fechada e que dava acesso à sala de casa, além dos "restos mortais" do antigo balanço de metal, também azul. Construía no quintal da minha casa, uma projeção imaginada da minha própria casa enquanto potencialidade de um futuro. Uma metonímia. A casa dentro da casa. Uma heterotopia. Uma utopia. Um ainda - não - sendo.

A contiguidade metonímica é o que aproxima minha memória de infância ao que vejo na videoperformance de Chubbeyoncé Lee. Em All about that bass, o espaço é uma metonímia no sentido de que é aditivo e associativo e opera para garantir uma qualidade contígua e de deslocamentos. No sentido da heterotopia, vejo o quintal da casa em que Lee e seus dançarinos se colocam para o mundo, num processo aditivo de outros espaços possíveis e dramaturgicamente "[...] um espaço que pode ser reconhecido [...] e, ao mesmo tempo uma espaço potencial, pronto a se despir de sua identidade para ser transformado pelas forças do espetáculo" (Barba, 2010, p.84). Barba (2010, p. 85) nos diz ainda que:

O espaço era um reino mágico que eu [ele] preenchia e esvaziava. Tecia ações reais, introduzia ao mesmo tempo várias situações que independiam umas das outras, modelava um ritmo ou uma ação [...] 
numa contiguidade de imagens e alusões.

Ou seja, Lee (re)organiza, contesta e (trans)forma os espaços-tempos existentes enquanto realidade direta, para então (re)inventa-los. Seu quintal contém potencialmente o estúdio de gravação, o palco do The Voice (narrativa de outra videoperformance) e é de fato o quintal, o palco que os projeta para o mundo.

Meu voo adentra ainda mais fundo nesse abismo e para além das imagens que se mostram, dos espaços evocados pela imaginação de Lee, dos corpos presentes e das ações executadas na realização da performance (ao vivo) para seu registro, entendendo que todas essas informações são transformadas em bits, a videoperformance de Lee é um registro eletrônico em vídeo postado no site da internet, YouTube. Em seu livro Cidades Ínvisíveis Ítalo Calvino constrói em seu texto, a cidade de Fedora, um espaço que muda e se transforma à medida que seus habitantes tentam idealiza-la.

No centro de Fedora, metrópole de pedra cinzenta, há um palácio de metal com uma esfera de vidro em cada cômodo. Dentro de cada esfera, vê-se uma cidade azul que é o modelo para uma outra Fedora. São as formas que a cidade teria podido tomar se, por uma razão ou por outra, não tivesse se tornado o que é atualmente. Em todas as épocas, alguém, vendo Fedora tal como era, havia imaginado um modo de transformá-la na cidade ideal, mas, enquanto construía o seu modelo em miniatura, Fedora já não era mais a mesma [...]. (Calvino, 1990a, p. 24).

Calvino nos mostra a efemeridade do objeto que se olha. Pensar em Fedora (cidade invisível) e sua permanente mudança e inalcançável apreensão é entendêla como anúncio do ciberespaço. Christine Mello (2008, p. 48/49) sugere que, com a apropriação das tecnologias de comunicação pela arte ocorreu uma mudança de percepção da dimensão espaço-tempo, para ela esta dimensão não pode mais ser apresentada separadamente, pois convive num mundo de espaços-tempos múltiplos e simultâneos, o ciberespaço. Nesse ciberespaço podemos destacar o YouTube como espaço de compartilhamento em que a produção das videoperformances de Lee se (re)dimensiona e se retroalimenta constantemente 
no/do fluxo midiático. De acordo com Henry Jenkins (2009, p. 348): "O YouTube emergiu como um site fundamental para a produção e distribuição da mídia alternativa - [...], causada pelo surgimento de novas formas de cultura participativa". "O YouTube transforma meros espectadores em ativos colaboradores" (Fernandes Júnior, 2015, p.29) e coaduna com o pensamento que Calvino desenvolveu uma década antes do grande boom das redes sociais.

O ciberespaço "uma vez que emerge das relações estabelecidas entre os vários elementos que o compõem - [...] - seria por definição, um espaço do tipo relacional" (Fragoso, 2000, p.110). Quando Lee posta seus vídeos no YouTube, o quintal de sua casa ganha dimensões espaço-temporais para além daqueles metros quadrados físicos e para além daquele momento específico. Aquela ação que estava sendo executada transforma-se em fluxo de energia. O YouTube então passa a ser seu ciberquintal.

Assim, como o oceano que Foucault nos fala na epígrafe, ou o céu em que se pode voar leve como o pássaro de Calvino, ou mesmo a cidade imaginária que se transforma sempre que tentamos fixá-la em um modelo ideal, Lee e seu TeamAspo não imaginaram apenas o navio para navegar no oceano, ou o pássaro para voar no céu de seu quintal, mas sim, também, transformaram-se em fluxo de elétrons, no ciberespaço explodindo as fronteiras físicas do quintal de sua casa, em Cebu, nas Filipinas, em mundo.

C

\section{$\operatorname{AFET(O)AÇÃO~}$}

$\mathrm{R}$

$\mathrm{P}$

O: DRAMATURGIA EM FLUXO

O processo de criação, como uma viagem no próprio microcosmo e um encontro com o próprio "outro", tornava-se o equivalente da viagem do emigrante numa geografia desconhecida. (Barba, 2010, p. 173). 
$\mathrm{Na}$ observação dos eventos midiáticos que compõem suas videoperformances, Lee amplia e cria possibilidades de (res)significar a própria existência enquanto aproximação da experiência do outro. Ouso aqui a chamar de exotopia, numa referência ao conceito criado por Bakhtin em (1922/1924) ${ }^{5}$ e que em sua natureza se comporta como uma metonímia. Exotopia tem como sentido "se situar em um lugar exterior" (Amorim, 2006, p.96) e consistiria em dois movimentos:

Primeiro o de tentar captar o olhar do outro, de tentar entender o que o outro olha, como o outro vê. Segundo, de retornar ao seu lugar, que é necessariamente exterior à vivência do retratado, para sintetizar ou totalizar o que vê, de acordo com seus valores, sua perspectiva, sua problemática. (Amorim, 2006, p. 96).

Bakhtin quando, ao tratar do conceito de exotopia ressaltou que: "Apesar de toda inseparabilidade dos mundos representados e representantes, apesar da irrevogável presença da fronteira rigorosa que os separa, eles estão indissoluvelmente ligados um ao outro e se encontram em constante interação" (Bakhtin, 1998, p. 358) ou "como o próprio Pablo Picasso disse, "eu pinto o que penso e não o que vejo'” (Amorim, 2006, p.97).

Quando escrevo este texto me coloco nesse lugar exterior para tentar totalizar, em forma de texto escrito, o que eu vejo nos trabalhos artísticos de Lee, num movimento metonímico, um mise em abyme como destaca Edinília Nascimento Cruz (2017, p. 5102):

A narrativa em abismo, ou procedimento de duplicação especular, é um mecanismo discursivo, que se manifesta nas mais variadas formas. O jogo narrativo por meio do efeito do mise em abyme, ou - redobramento especular da narrativa, funciona como um espelho. [...].

Nas várias camadas de observação: eu olho seu ciberquintal e de meu lugar externo e exotópico tento sintetizar a sua totalidade ao (re)criar e (res)significar o

${ }^{5}$ De acordo com Marília Amorim essas datas foram fornecidas por Todorov na lista cronológica dos escritos de Bakhtin e de seu Círculo. Marília Amorim, 2006, p. 95-114. 
que ele vê do videoclipe da Meghan Trainor. Na sua produção, o que poderia ser descrito como cópia ou paródia do original, é já original em si, enquanto síntese de uma alteridade, um fruto dos encontros.

A historiadora cultural Mary Louise Pratt descreve, a partir do estudo de um manuscrito peruano de 1613, o que chama de artes da zona de contato, tendo como zona de contato, os "espaços sociais onde culturas díspares se encontram, se chocam, se entrelaçam uma com a outra, frequentemente em contextos de alta assimetria das relações de poder"” (Pratt, 1991, p.34). Essa afirmativa de Pratt (1991) é retomada por Jenkins (2009, p.348) como uma característica do YouTube quando diz que esta plataforma: “[...] representa o encontro entre uma série de comunidades alternativas diversas, cada uma delas produzindo mídia independente [...]”. Já as artes da zona de contato são definidas por Jenkins; Green; Ford (2014, p. 319) como "um composto cultural cuja identidade sofreu mash-ups e remixes e é marcada por uma série de passagens fronteiriças, momentos em que as duas culturas (talvez mais) se interligam, vencendo distancias geopolíticas”, que produzem novas/outras possibilidades dramatúrgicas.

É importante ressaltar que o entendimento de dramaturgia nesse texto se dá a partir da chave etimológica proposta por Eugenio Barba: drama-ergein ou trabalho das ações e da definição exposta por Paulo Caldas e Ernesto Gadelha (2016, p. 13), qual seja:

O fazer dramatúrgico se quer, portanto plural, errático, transversal, distributivo e expansível, sobre variados domínios cênicos e artísticos, nutrido por variados domínios não necessariamente cênicos nem artísticos, ligado a uma poética de sentido inscrita no espaço-tempo singular de cada obra - de cada uma de suas efetuações performativas -, operando das mediatas decisões das salas de ensaio até as imediatas decisões que modulam um gesto cada vez que é performado.

Assim o sentido dramatúrgico aqui pensado diz de um fazer ligado aos sentidos, materiais e tessituras que ultrapassam a dimensão do texto e se faz

${ }^{6}[\ldots]$ social spaces where cultures meet, clash, and grapple with each other, often in contexts of highly asymetrical relations of power [...]. (Tradução nossa) 
como coprodutor de cena e encenação. (Caldas; Gadelha, 2016).

All about that bass, apresenta várias decisões dramatúrgicas em sua composição, a saber: a escolha dos espaços para a realização de cada ação que é apresentada em sua videoperformance; a relação frontal com a câmera; as ações que acontecem fora do enquadramento da câmera; as escolhas de material cênico e sua utilização nas ações; a escolha de não editar os prováveis erros de enquadramento que revelam ações que, supostamente, não deveriam aparecer; a definição de como iniciar o vídeo surgindo no enquadramento da câmera; o uso da perspectiva tanto na composição coreográfica quanto na composição das imagens e a escolha da música para a dublagem. Estas decisões para a composição de sua videoperformance são referenciadas nas narrativas que são construídas e divulgadas pela cultura visual pop, mais especificamente norte americana, desde o surgimento do videoclipe musical em meados da década de 1980. Apesar da força massificadora dessas narrativas impostas pela indústria visual e musical norte americana Lee consegue trazer informações que são de sua própria cultura em sua movimentação coreográfica, são os mash-ups e remixes que nos falam Jenkins; Green; Ford (2014). Estas decisões se apresentam em All about that bass como o que Barba (2010, p. 149) chamou de lógica do nivel narrativo, pois tem a função de "amarrar as relações e tecer associações". Ainda segundo o autor: "A ação pode ser pensada e elaborada como uma montagem simultânea de vários componentes, que interagindo, criam sensações e significados imprevistos e diferentes para cada espectador." (Barba, 2010, p.153).

All about that bass também demonstra o envolvimento afetivo, emocional e habitual das narrativas da cultura pop e sua música, com seu público alvo. Para pensar na dimensão do afeto, faço mais um breve movimento autoetnográfico.

Eu sou um fã fiel da Madonna. Vivi as décadas de 1980, 1990 e 2000 acompanhando initerruptamente as investidas dessa artista na construção de sua carreira e tentando cá, na minha realidade de homem, gay, branco, cis, brasileiro, do interior da Bahia, me aproximar desse ideal. Assistia aos shows televisionados, aos videoclipes. Gravava em fitas cassete todas as músicas e aprendia as letras 
para cantar no meu então inglês embromation?. Já mais tarde, quando de meu tempo vivendo em Phoenix, no Arizona, quase não dormi na noite anterior ao show da turnê Confessions on a Dance Floor. É, eu sou fã da Madonna! Sei que minha admiração/fascínio por sua imagem de mulher independente, de atitude e um trabalho artístico impecável estabeleceu fortes marcas em meu imaginário e trabalho como artista.

O reconhecimento desse fato é o que chama minha atenção e me conecta com as videoperformances de Lee que é fã da Beyoncé. Reconheço o afeto produzido na relação dele com seu ídolo. O afeto aqui se estabelece enquanto dimensão que mobiliza estados de existência dos corpos. O afeto implica na ação. Deixar-se ou não ser afetado é definido a partir dos encontros que temos na vida. Para Antônia Pereira Bezerra (2010, p.18) "o ser humano não é ilha, prisão, essência. Ele se define por seus contatos, pela maneira de compreender o mundo e de se compreender". As imagens midiáticas das cantoras da indústria musical pop em sua maioria, mulheres de personalidade forte, estabelecem afecções que criam mitologias pessoais (Jenkins, 2009, p.30). Materno nos diz que entre o visível e o legível reivindica-se ao pensamento da imagem um espaço-tempo que são ambíguos, sem âncoras em dicotomias usuais e simplistas e que "a captura da significação de algo é sempre novamente provisória” (Materno, 2003, p. 34). Daí vem as narrativas e estas "tem uma relação não com a realidade em si, mas com uma consciência que compreende esta realidade, isto é, ela amplia ou inventa realidades ao produzir significações" (Bezerra, 2010, p.21). Dessa forma, esses encontros mobilizam o criar, um criar imerso e (retro)alimentado por um fluxo inestancável de trocas e nesse processo tornam-se mídias de si mesmos (Katz; Greiner, 2005).

O corpo, lugar dessas afecções, é quem revela se este afeto aumenta ou diminui a potência dessa ação. O corpo é o primeiro aspecto em nossa relação no/com o mundo e esse corpo não é estanque ou limitado ou definitivo ou imutável, mas sim o resultado de trocas que se dão nas relações corpo-ambiente.

(gíria) - Embromação (enganação, mentira) na hora de falar ou cantar em inglês; Enrolação. Disponível em: https://www.dicionarioinformal.com.br/significado/embromation/3083/. Acesso em: 28 abr. 2020. 
Para Helena Katz e Christine Greiner (2005, p. 130) há uma “implicação do corpo no ambiente, que cancela a possibilidade de entendimento do mundo como um objeto aguardando um observador". Para as autoras "algumas informações do mundo são selecionadas para se organizar em forma de corpo" (Katz; Greiner, 2005, p. 130) entende-se com isso que corpo não é um recipiente, mas sim um processo de trocas com o ambiente, ou seja, corpo é "aquilo que se apronta no processo." (Katz; Greiner, 2005, p. 131).

Se corpo é isso que se apronta no processo de negociação das informações com o ambiente, pensar e criar nesse fluxo possui modos de (re)elaborar, (re)construir e (re)criar sentidos, significações, narrativas e dramaturgias como potências artísticas a partir de referenciais afetivos, como uma ação/movimento/questionamento que se faz crítica, intersecciona, ousa e gera produções que se auto constituem enquanto postura performativa.

\section{Referências}

AMORIM, Marília. Cronotopo e exotopia. In: BRAIT, Beth. Bakhtin: outros conceitos-chave. São Paulo: Contexto, 2006, p. 95 -114.

BACHELARD, Gaston. A poética do espaço. São Paulo: Martins Fontes, 1993.

BAKHTIN, Mikhail. Questões de literatura e de estética. São Paulo:

UNESP/HUCITEC, 1998, p. 349-362.

BARBA, Eugênio. Queimar a casa: origens de um diretor. Tradução: Patrícia Furtado de Mendonça. São Paulo: Perspectiva, 2010.

BEZERRA, Antonia Pereira. Alteridade, Memória e Narrativa: construções dramáticas. São Paulo: Perspectiva: CNPq, 2010.

CALDAS, Paulo; GADELHA, Ernesto (Orgs.). Dança e Dramaturgia[s]. Fortaleza: São Paulo: Nexus, 2016.

CALVINO, Ítalo. As Cidades Invisíveis. São Paulo: Companhia das Letras, 1990a.

CALVINO, Ítalo. Seis propostas para o próximo milênio. São Paulo: Companhia das Letras, 1990b. 
CANCLINI, Nestor Garcia. A sociedade sem relato: Antropologia e Estética da Iminência. São Paulo: EDUSP, 2012.

CRUZ, Edinília Nascimento. Narrativas mise en abyme: a estrutura em abismo de corpo de baile. Anais ABRALIC, 2017, p. 5100 - 5107. Disponível em: http://www.abralic.org.br/anais/arquivos/2017 1522245230.pdf, Acesso: 21 nov. 2019.

FERNANDES JÚNIOR, Aroldo Santos. Biscoitos caseiros: camp, solidão e homofobia na internet. Curitiba: Appris, 2015.

FOUCAULT, Michel. O corpo utópico, As heterotopias. Posfácio de Daniel Defert. Tradução: Salma Tannus Muchail. São Paulo: n-1 Edições, 2013.

FRAGOSO, Suely. Espaço, Ciberespaço, Hiperespaço. Textos de Comunicação e Cultura, n.42. UFBA, 2000, p. 105-116.

JACOBY, Russell. Imagem Imperfeita: Pensamento utópico para uma época antiutópica. Rio de Janeiro: Civilização Brasileira, 2007.

JENKINS, Henry; GREEN, Joshua; FORD, Sam. Cultura da conexão: criando valor e significado por meio da mídia propagável. São Paulo: Aleph, 2014.

JENKINS, Henry. Cultura da convergência. São Paulo: Aleph, 2009.

KATZ, Helena; GREINER, Christine. Por uma teoria do corpomidia. In: GREINER, Christine. O corpo: pistas para estudos indisciplinares. São Paulo: Annablume, 2005, p. $125-134$.

LEE, Royce Cherdan. All about that bass. Disponivel em:

https://www.youtube.com/watch?v=X1bhpWQDT-4. Acesso em: $21 \mathrm{de}$ abr. 2020.

MACHADO, Arlindo. Arte e Mídia. Rio de Janeiro: Jorge Zahar Ed., 2008.

MEIGH-ANDREWS, Chris. A History of Video Art. New York: London: New Delhi; Sydney: Bloomsbury, 2014.

MATERNO, Angela. O olho e a Névoa: considerações sobre a teoria do teatro. Sala Preta. São Paulo, n.3, 2003, p. 31-41.

MELLO, Christine. Extremidades do vídeo. São Paulo: SENAC São Paulo, 2008.

PRATT, Mary Louise. Arts of contact zone. In: FRANKLYN, Phyllis (Ed.). Profession 91. New York: Modern Language Association of America, 1991, p. 33-40. Disponível em: http://www.jstor.org/stable/25595469. Acesso em: 21 de abr. 2020.

TRAINOR, Meghan. All About That Bass (Official Music Video). Disponível em: 
https://www.youtube.com/watch?v=7PCkvCPvDXk. Acesso em: 21de abr. 2020.

Recebido em: 20/05/2020

Aprovado em: 13/07/2020 